\title{
Pengaruh Pemanfaatan Media Tutorial Berbentuk Film Motion Pictures Terhadap Motivasi Belajar Siswa
}

\author{
Nurul Perdana Putri, Hadi Gunawan Sakti \\ Program Studi Teknologi Pendidikan, Fakultas Ilmu Pendidikan dan Psikologi Universitas \\ Pendidikan Mandalika Mataram \\ Corresponding Author. Email: gunawansakti33@gmail.com
}

\begin{abstract}
The purpose of this study was to determine the effect of using tutorial media in the form of motion pictures on student motivation in class $\mathrm{X}$ ICT subjects at MA Darul Qur'an Wal Hadits. This research method using experiment. The population in this study were all students of class X at MA Darul Qur'an Wal Hadits 101 with a sample of 30 students. Data collection techniques in this study used a documentation questionnaire, observation and interviews. The data analysis technique used the t-test. From the research results obtained t-test of 3.481 with a significance level of $5 \%$ and d.b N-1 = $(30-1=29)$ of 2.045 . This shows that Ho is rejected and Ha is accepted, so it is concluded that there is an effect of the use of tutuorial media in the form of motion pictures on students' learning motivation in the $\mathrm{X}$ grade typology subject at MA Darul Qur'an Wal Hadits.
\end{abstract}

Abstrak: Tujuan penelitian ini adalah untuk mengetahui pengaruh pemanfaatan media tutorial berbentuk film motion pictures terhadap motivasi belajar siswa pada mata pelajaran TIK kelas X di MA Darul Qur'an Wal Hadits. Metode penelitian ini menggunakan eksperimen. Populasi dalam penelitian ini adalah seluruh siswa kelas X di MA Darul Qur'an Wal Hadits 101 dengan sampel berjumlah 30 siswa. Teknik pengumpulan data dalam penelitian ini menggunakan angket dokumentasi, observasi dan wawancara. Teknik analisis data menggunakan t-test. Dari hasil penelitian diperoleh t-tes sebesar 3,481 dengan taraf signifikansi 5\% dan d.b N-1 =(30-1=29) sebesar 2,045. Hal ini menunjukan bahwa Ho ditolak dan Ha diterima, maka disimpulkan bahwa ada pengaruh pemanfaatan media tutuorial berbentuk film motion pictures terhadap motivasi belajar siswa pada mata pelajaran tik kelas $\mathrm{X}$ di MA Darul Qur'an Wal Hadits.
Article History

Received: 26-02-2021

Revised: 19-03-2021

Published: 14-04-2021

Key Words:

Tutorial Media,

Film Motion

Pictures, Students'

Learning

Motivation.

\section{Sejarah Artikel}

Diterima: 26-02-2021

Direvisi: 19-03-2021

Diterbitkan: 14-04-2021

\section{Kata Kunci:}

Media Tutorial, Film

Motion Pictures, Motivasi

Belajar.

How to Cite: Putri, N., \& Sakti, H. (2021). Pengaruh Pemanfaatan Media Tutorial Berbentuk Film Motion Pictures Terhadap Motivasi Belajar Siswa. Jurnal Teknologi Pendidikan : Jurnal Penelitian dan Pengembangan Pembelajaran, 6(1). doi:https://doi.org/10.33394/jtp.v6i1.3617

do

https://doi.org/10.33394/jtp.v6i1.3617

This is an open-access article under the CC-BY-SA License.

\section{Pendahuluan}

Teknologi pendidikan merupakan suatu bidang kajian khusus ilmu pendidikan. Belajar bukan hanya dilakukan oleh individu, melainkan oleh kelompok, bahkan juga diperuntukkan oleh organisasi secara keseluruhan. Dengan adanya teknologi pendidikan, maka dapat belajar di mana saja, kapan saja, pada siapa saja, mengenai apa saja, dengan cara dan sumber dari mana saja, disesuaikan dengan kondisi dan kebutuhan.Teknologi pendidikan adalah teori dan praktik dalam desain, pengembangan, pemanfaatan, pengelolaan, serta evaluasi tentang proses dan sumber untuk belajar" AECT (dalam Januszewski, 2008). Definisi ini menegaskan adanya lima domain (kawasan) teknologi pendidikan, yaitu kawasan desain, kawasan pengembangan, kawasan pemanfaatan, kawasan pengelolaan, dan kawasan 
penilaian baik untuk proses maupun sumber belajar. Seorang teknologi pendidikan bisa saja memfokuskan bidang garapannya dalam salah satu kawasan tersebut. Aplikasi teknologi pendidikan juga tidak terlepas dari lima kawasan tersebut. Seels \& Richey (dalam Januszewski, 2008) yang menjelaskan bahwa "demi menjaga keutuhan definisi kegiatankegiatan dalam setiap kawasan teknologi pendidikan dapat dikaitkan baik kepada proses maupun sumber pembelajaran".

Pendidikan merupakan sumber daya insani yang sepatutnya mendapatkan perhatian terus menerus dalam upaya peningkatan mutunya. Peningkatan mutupendidikan berarti pula peningkatan kualitas sumber daya manusia. Untuk itu perlu dilakukan pembaruan dalam bidang pendidikan dari waktu ke waktu tanpa henti. Sistem pendidikan nasional senantiasa harus dikembangkan sesuai dengan kebutuhan dan perkembangan yang terjadi baik ditingkat lokal,nasional, maupun global.

"Pendidikan merupakan suatu usaha yang dilakukan secara sadar dengan sengaja untuk mengubah tingkah laku manusia baik secara individu maupun kelompok untuk mendewasakan manusia melalui upaya pengajaran dan latihan" (dalam Sugihartono, dkk, 2007). Pendidikan dapat diperoleh secara formal maupun informal. Pendidikan yang dibahas sekarang ini adalah pendidikan formal yaitu pendidikan yang diadakan pada lingkup sekolah.Melalui pendidikan inilah berbagai aspek kehidupan dikembangkan melalui proses belajar dan pembelajaran. Proses pembelajaran pada hakikatnya diarahkan untuk membelajarkan siswa agar dapat mencapai tujuan yang telah ditentukan. Artinya, siswa harus dijadikan sebagai pusat dari segala kegiatan, sehingga dalam perencanaan dan mendesain pembelajaran harus disesuaikan dengan kondisi siswa yang bersangkutan.

Berdasarkan hasil observasi dengan guru mata pelajaran TIK Pada kondisi awalnya cara guru mengajar di MA Darul Qur'an Wal Hadits khususnya guru TIK rata-rata mengajar dengan metode ceramah, dan diskusi kelompok. Salah satu untuk mengatasi permasalahan diatas, adalahmedia tutorial berbentuk film (Motion Picture). Susilana, (2007) berpendapat bahwa "Film (Motion Pictures)disebut juga gambar hidup (motion pictures)', yaitu serangkaian gambar diam(skill picture) yang meluncur secara cepat dan diproyeksikan sehingga menimbulkan kesan hidup dan bergerak. Film merupakan media yang menyajikan pesan audio visual dan gerak. Oleh sebab itu, film memberikan kesan yang impresif bagi pemirsannya.Keuntungan Media Film ini sangat menguntungkan bagi pendidik yaitu : 1) Memberikan pesan yang dapat diteima secara lebih merata oleh siswa.2) Sangat bagus untuk menerangkan suatu proses. 3) Mengatasi keterbatasan ruang dan waktu. 4) Lebih realistis, dapat diulang-ulang dan dihentikan sesuai dengan kebutuhan. 5) Memeberikan kesan yang mendalam, yang dapat mempengaruhi sikap siswa.

Pembelajaan perlu dipahami oleh pendidik agar dapat melakukan berbagai bentuk tindakan atau bantuan kepada siswa. Motivasi belajar merupakan suatu keadaan yang terdapat pada diri seseorang individu dimana ada suatu dorongan untuk melakukan sesuatu guna mencapai tujuan. Sedangkan menurut Dalyono (2005) bahwa "Motivasi adalah daya penggerak/pendorong untuk melakukan suatu pekerjaan, yang bisa berasal dari dalam diri dan juga dari luar".

Dari hasil observasi pengajaran TIK di Ma Darul Qur'an Wal Hadits Telaga Lebur Sekotong Tengah Kabupaten Lombok Barat ditemukan beberapa kelemahan diantaranya adalah prestasi belajar TIK yang dicapai siswa masih rendah. Fakta tersebut ditunjukan oleh nilai hasil belajar TIK siswa MA Darul Qur'an Wal Hadits Telaga Lebur Sekotong Tengah Kabupaten Lombok Barat dibawah KKM dengan rata-rata 56,00 diperoleh 21 siswa, sedangkan yang mendapat di atas KKM dengan rata-rata 80,00 diperoleh 9 siswa dengan 
jumlah keseluruhan 30 siswa. Berdasarkan observasi awal di MA Darul Qur'an Wal Hadits ditemukanbeberapa masalah pada guru yang sedang dihadapi pada pemberian materi dan sekaligus penyajian materi yang diberikan guru kurangbervariasidalam menjelaskan bahanbahan pelajar, yaituhanya menggunakan papan tulis dan cara pembelajaranya seperti ceramah dan belajar kelompok. Dalam mata pelajaran TIK guru juga kebanyakan hanya menjelaskan teori di dalam kelas yang sifatnya murid hanya menonton gurunya dan kebanyakan catatan siswa hilang tanpa memahami apa yang telah dipelajari di dalam kelas danfasilitas yang kurang memadai sehingga menyebabkan siswa kurang termotivasi dalam belajarnya. Dalam situasi seperti ini, guru dituntut dapat memilihbahan ajar yang dapat memacu semangat setiap siswa untuk secara aktif ikut terlibat dalam pengalaman belajarnya di dalam kelas dan diluar kelas. Media Tutorial berbentuk Film (Motion Pictures) sangat cocok dengan kondisi yang ada di sekolah MA Darul Qur'an Wal Hadits terutama yang sedang dihadapi guru yang dikarenakan keterbatasan dengan media pengajaran seperti ceramah dan belajar kelompok.

Pemilihan media Tutorial berbentuk Film (Motion Pictures)terhadap motivasi belajar siswa ini diharapkan mampu meningkatkan prestasi belajar siswa pada mata pelajaran khususnya TIK, karena didalam prosesnya pengaruh pembelajaran ini membuat siswa termotivasi melalui penyajian materi, yang sehingga lebih aktif dalam mengikuti pembelajaran dan memberikan pengalaman langsung kepada siswa cara belajar denganTutorial berbentuk Film (Motion Pictures). Adapun tujuan penelitian ini adalah untuk menganalisis pengaruh pemanfaatan media tutorial berbentuk film motion pictures terhadap motivasi belajar siswa pada mata pelajaran TIK Kelas X di MA Darul Qur'an Wal Hadits Telaga Lebur Sekotong Tengah Kabupaten Lombok Barat.

\section{Metode Penelitian}

Metode penelitian ini adalah eksperimen. Sugiyono (2015) menjelaskan metode penelitian eksperimen adalah metode penelitian yang digunakan untuk mencari pengaruh treatment tertentu(perlakuan) dalam kondisi yang terkontrol (laboratorium). Jenis metode eksperimen yang digunakan dalam penelitian ini adalah teknik studi populasidengan strategi One group pretest posttest design. Design dalam jenis penelitian ini terdapat pretest sebelum diberi perlakuan dan posttest sesudah diberi perlakuan. Dengan demikian, hasil penelitian dapat diketahui lebih akurat, karena dapat membandingkan dengan keadaan sebelum diberi perlakuan dengan sesudah diberi perlakuan. Desain ini dapat digambarkan 3.1 sebagai berikut:

\begin{tabular}{l}
\hline $\mathrm{O}_{1} \mathrm{X} \mathrm{O}_{2}$ \\
$\mathrm{O}_{1}=$ Pretest (nilai sebelum treatment) \\
$\mathrm{X}=$ Treatment \\
$\mathrm{O}_{2}=$ Posttest(nilai sesudah treatment)
\end{tabular}

Adapun sampel dalam penelitian ini adalah salah satu kelas $\mathrm{X}$ yang akan diundi atau diacak sehingga menjadi sampel penelitian, karena jumlah populasi kelas X di MA Darul Qur'an Wal Hadits Telaga Lebur Sekotong tengah berjumlah 101 maka pengambilan sampel menggunakan teknik claster random sampling, teknik random sampling adalah teknik pengambilan sampel berdasarkan kelas yang telah diundi atau diacak, maka yang menjadi sampel dalam penelitian ini adalah siswa kelas X A yang berjumlah 30 orang.

Teknik pengumpulan data yang digunakan adalah angket sebagai metode pokok dan observasi, wawancara, serta dokumentasi sebagai metode pelengkap. Sehubungan dengan 
penelitian ini, maka sesuai dengan gejala yang diteliti maka rumus yang digunakan adalah analisis data statistik dengan rumus t-test.

\section{Hasil Penelitian dan Pembahasan}

Berdasarkan hasil perhitungan t-test yang diperoleh melalui analisis, ternya nilai $\mathrm{t}$ diperoleh $=3,481$ kemudia dikonsultasiakn dengan $\mathrm{t}$ dalam tabel dengan $\mathrm{db}(\mathrm{N}-1)=30-1=$ 29 dengan taraf signifikansi $5 \%=2,045$. Dengan demikian, nilai t-hitung hasil penelitian ini lebih besar dari nilai t-tabel yakni 3,481>2,045, maka hipotesis alternative (Ho) ditolak dan (Ha) diterima pada taraf signifikansi $5 \%$ berarti ada pengaruh pemanfaatan media tutorial berbentuk film (Motion Pictures) terhadap motivasi belajar siswa pada mata pelajaran TIK kelas X di Ma Darul Qur'an Wal Hadits Telaga Lebur Sekotong Tengah. “signifikan” Sesuai dengan data yang diperoleh dan setelah dianalisis menggunakan rumus $t$-test dapat diketahui $\mathrm{o}_{1}=4,027$ adalah nilai sebelum melakukan tindakan (pre test) dan $\mathrm{o}_{2}=4,275$ adalah nilai setelah melakukan tindakan (post test), sedangkan $\mathrm{d}=103$ adalah nilai mean deviasi dari post test dan pre test, dan $\Sigma x^{2} \mathrm{~d}=847,366$ adalah nilai hasil perpangkatan xd, setelah semua nilai telah diketahui maka dari hasil uji t-test menunjukan nilai $t_{\text {hitung }}$ sebesar 3,481 maka berdasarkan taraf signifikansi 5\% dan d.b $=30$ ternyata besarnya angka batas penolakan hipotesis nihil (Ho) yang dinyatakan dalam tabel distribusi $t_{\text {tabel }}$ adalah 2,045 yang menunjukan bahwa nilai $t_{\text {hitung }}$ lebih besar dari pada nilai $t_{\text {tabel }}(3,481>2,045)$ karena $t_{\text {hitung }}$ lebih besar dari $t_{\text {tabel }}$ maka penelitian ini signifikansi. Hal ini berarti bahwa hipotesis nihil (Ho) yang diajukan ditolak dan sebaliknya hipotesis alternatif (Ha) yang diajukan diterima, maka dapat ditarik kesimpulan bahwa terdapat “ Pengaruh pemanfaatan media tutorial berbentuk film (Motion Pictures) terhadap motivasi belajar siswa pada mata pelajaran TIK kelas X di MA Darul Qur'an Wal Hadits Telaga Lebur Sekotong Tengah Kabupaten Lombok Barat.

Berdasarkan data hasil penemuan dalam penelitian, yang kemudian dimasukkan ke dalam tabel kerja serta dianalisis dengan cara memasukannya ke dalam rumus $t$-test, yang kemudian mengkonsultasikan nilai t-hitung dengan nilai $\mathrm{t}$-tabel pada taraf signifikansi $5 \%$, dan dibandingkan dengan teori-teori di atas, maka penelitian ini dapat dikatakan signifikan.Hal ini dibuktikan dengan data tabel kerja yang menunjukkan bahwa nilai post-test lebih besar dari nilai pre-test (4.275>4.027). Dan hasil analisis data yang menunjukkan nilai t-hitung sebesar 3,481 dan nilai t-tabel pada taraf signifikansi 5\% dengan $\mathrm{df}=\mathrm{N}-1=30-1=29$ sebesar 2,045. Penemuan ini menunjukkan bahwa, $t$-hitung lebih besar dari $t$-tabel $(3,481>2,045)$. Maka $\mathrm{H}_{0}$ ditolak dan Ha diterima. Berdasarkan pembahasan tentang pelaksanaan penelitian dan hasil analisis data di atas, yang kemudian dibandingkan dengan semua teori tentang pembelajaran media film berbentuk (Motion Pictures), maka dapat disimpulkan bahwa penelitian yang telah dilakukan dengan menggunakan pembelajaran media tutorial berbentuk film (Motion Pictures), ini dinyatakan signifikan, dengan hasil analisis data yang menunjukkan nilai $\mathrm{t}$-hitung lebih besar dari nilai $t$-tabel $(3,481>2,045)$. Dengan kata lain, hasil analisis data tersebut menunjukkan bahwa nilai $\mathrm{t}$-hitung berada di atas angka batas penolakan dalam $\mathrm{t}$-tabel dengan taraf signifikansi $5 \%$ dan $\mathrm{df}=\mathrm{N}-1=30-1=29$ yaitu $(3,481>2,045)$. Sehingga dapat disimpulkan juga bahwa hipotesis nihil $\left(\mathrm{H}_{0}\right)$ ditolak dan sebaliknya hipotesis alternatif $(\mathrm{Ha})$ diterima.Sehingga dapat dikatakan bahwa terdapat "Pengarauh Pemanfaatan Media Tutorial berbentuk Film (Motion Pictures) terhadap Motivasi Belajar Siswa Pada Mata Pelajaran TIK Kelas X di MA Darul Qur'an Wal Hadits Telaga lebur Sekotong Tengah Kabupaten Lombok Barat". 


\section{Kesimpulan}

Berdasarkan hasil analisis data, maka dapat disimpulkan bahwa: "terdapat pengaruh pemanfaatan media tutorial berbentuk film (motion pictures) terhadap motivasi belajar siswa pada mata pelajaran TIK kelas X di MA Darul Qur'an Wal Hadits Telaga Lebur Sekotong Tengah". Hal inidapat dilihat dari hasil penelitian yaitu nilai thitungsebesar 3,481 dan nilai $t$ tabelpada taraf signifikansi $5 \%$ dengan d.b $(\mathrm{N}-1)=30$, lebih besar dari pada nilai $t$ tabel( $3,481>2,045)$, sehingga dapat disimpulkan hasil penelitian ini signifikan.

\section{Saran}

Berdasarkan hasil penelitian yang telah diperoleh, peneliti dapat memberikan saran-saran kepada: (1). Kepala Sekolah, Hendaknya selalu memberikanmotivasi kepadaguru bidang studi, wali kelas, dan pihak-pihak lain dalam penggunaan media pembelajaran yang bervariasi agar hasil belajar siswa lebih baik. (2). Kepada Guru, Hendaknya dalam pembelajaran TIK dapat menggunakan media tutorial berbentuk film (Motion Pictures) sebagai alternatif pembelajaran agar siswa dapat lebih terotivasi dan aktif serta tidak merasa jenuh dalam proses pembelajaran, sehingga hasil belajar siswa dapat meningkat. (3). Kepada Siswa, Sebagai subyek hendaknya betul-betul mengikuti proses pembelajaran agar pembelajaran berlangsung dengan baik, betul-betul memanfaatkan semua sumber belajar, sehingga dapat meningkatkan hasil belajar dan termotivasi.

\section{Daftar Pustaka}

Anni, Chatarina Tri. (2006). Psikologi Belajar. Semarang: UPT UNNES Press.

Azhar, Arsyad. (2002). Media Pembelajaran. Divisi Buku Perguruan Tinggi PT. Raja Garfindo Persada (Rajawali Press), Jakarta.

Dalyono, M. (2005).Psikologi Pendidikan. Jakarta: Rineka Cipta

Daryanto. (2010). Media Pembelajaran Peranannya Sangat Penting Dalam Mencapai Tujaun Pembelajaran. Yogyakarta: Gava Media.

Hamzah B. Uno \& Nina Lamatenggo. (2011). Teknologi Komunikasi dan Informasi Pembelajaran. Jakarta: Bumi Aksara.

Hamzah. B. Uno. (2007). Teori Motivasi dan Pengukurannya, Jakarta: Bumi Aksar Handayani, L. (2020). Peningkatan Motivasi Belajar IPA Melalui Model Pembelajaran Project Based Learning pada Masa Pandemi Covid-19 bagi Siswa SMP Negeri 4 Gunungsari. Jurnal Paedagogy, $\quad 7(3), \quad$ 168-174. doi:https://doi.org/10.33394/jp.v7i3.2726

Januszewski, A \& Molenda, M. (2008). Educational Technology. Taylor \& Prancis Group. New York

Munir, M. (2015). Multi Media. Jakarta: Rinega Cipta

Nuryaningsih, W. (2021). Penerapan Media Schoology untuk Meningkatkan Motivasi dan Hasil Belajar Siswa dalam Pembelajaran Bahasa Indonesia di SMP Negeri 3 Bojong Pekalongan. Jurnal Paedagogy, 8(1), 16-23. doi:https://doi.org/10.33394/jp.v8i1.3161

Rohani Ahmad. (2014). Media Intruksional Edukatif. Jakarta: Rineka Cipta

Sadiman, A.M. (2011). Interaksi dan Motivasi Belajar Mengajar. Jakarta Grafindo Persada

Setioyosari, P. dan Shikabuden. (2008). Media Pembelajaran. Malang: Elang Mas

Sianipar P. (2005). Animasi Klip. Jakarta: Komput Indo

Suarni, G., Rizka, M., \& Zinnurain, Z. (2021). Analisis Pengaruh Penerapan Model Pembelajaran Sains Teknologi Masyarakat Terhadap Hasil Belajar Siswa. Jurnal Paedagogy, 8(1), 31-38. doi:https://doi.org/10.33394/jp.v8i1.3226 
Sugiyono. (2015). Metode Penelitian Pendidikan Pendekatan Kuantitatif, Kualitatif, dan $R \& D$. Bandung. Alfabeta.

Susmiati, E. (2020). Meningkatkan Motivasi Belajar Bahasa Indonesia Melalui Penerapan Model Discovery Learning dan Media Video Dalam Kondisi Pandemi Covid-19 bagi Siswa SMPN 2 Gangga. Jurnal Paedagogy, 7(3), 210-215. doi:https://doi.org/10.33394/jp.v7i3.2732

Susilana, Rudi \& Riyana, C. (2007). Media Pembelajaran, Hakikat, Pengembangan, Pemanfaatan, dan Penelitian. Bandung: Bumi Rancaek Kencana.

Widyastuti, Sri Harti \& Nurhidayati. (2010). Pengembangan Media Pembelajaran. Universitas Negeri Yogyakarta: Program Studi Bahasa Jawa

Wind, Ajeng. (2014). Jago Membuat Video Tutorial. Jakarta: Niaga Swadaya 